\title{
Predictive value of multidrug resistance proteins and cellular drug resistance in childhood relapsed acute lymphoblastic leukemia
}

\author{
Jan Styczynski · Mariusz Wysocki · Robert Debski $\cdot$ Krzysztof Czyzewski $\cdot$ Beata Kolodziej · \\ Beata Rafinska • Malgorzata Kubicka · Sylwia Koltan · Andrzej Koltan · Monika Pogorzala • \\ Andrzej Kurylak · Dorota Olszewska-Slonina $\cdot$ Walentyna Balwierz $\cdot$ Edyta Juraszewska $\cdot$ \\ Maria Wieczorek · Igor Olejnik · Maryna Krawczuk-Rybak · Marta Kuzmicz · Jerzy Kowalczyk • \\ Jolanta Stefaniak · Wanda Badowska · Danuta Sonta-Jakimczyk · Tomasz Szczepanski · \\ Michal Matysiak · Iwona Malinowska - Elzbieta Stanczak · Jacek Wachowiak - Benigna Konatkowska • \\ Lidia Gil · Anna Balcerska · Lucyna Maciejka-Kapuscinska
}

Published online: 22 August 2007

(C) Springer-Verlag 2007

\section{Erratum to: J Cancer Res Clin Oncol DOI 10.1007/s00432-007-0274-1}

The names of the last five authors were mistakenly deleted during production. The full list of authors and their affiliations are given here.

The online version of the original article can be found under doi:10.1007/s00432-007-0274-1.

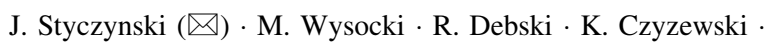

B. Kolodziej · B. Rafinska · M. Kubicka · S. Koltan ·

A. Koltan - M. Pogorzala · A. Kurylak

Department of Pediatric Hematology and Oncology, Collegium Medicum, Nicolaus Copernicus University, ul. Curie-Sklodowskiej 9, 85-094 Bydgoszcz, Poland e-mail: jstyczynski@cm.umk.pl

D. Olszewska-Slonina

Department of Biology, Collegium Medicum,

Nicolaus Copernicus University, Bydgoszcz, Poland

W. Balwierz $\cdot$ E. Juraszewska

Department of Pediatric Hematology and Oncology, CMUJ, Krakow, Poland

M. Wieczorek · I. Olejnik

Department of Pediatric Hematology and Oncology,

Pediatric Center, Chorzow, Poland

M. Krawczuk-Rybak · M. Kuzmicz

Department of Pediatric Hematology and Oncology,

Medical University, Bialystok, Poland

J. Kowalczyk · J. Stefaniak

Department of Pediatric Hematology and Oncology,

Medical University, Lublin, Poland
W. Badowska

Department of Pediatric Hematology and Oncology,

WSSD, Olsztyn, Poland

D. Sonta-Jakimczyk · T. Szczepanski

Department of Pediatric Hematology and Oncology,

Medical University, Zabrze, Poland

M. Matysiak · I. Malinowska $\cdot$ E. Stanczak

Department of Pediatric Hematology and Oncology,

Medical University, Warszawa, Poland

J. Wachowiak · B. Konatkowska

Department of Pediatric Hematology and Oncology,

Medical University, Poznan, Poland

L. Gil

Department of Hematology, Medical University, Poznan, Poland

A. Balcerska · L. Maciejka-Kapuscinska

Department of Pediatric Hematology,

Oncology and Endocrinology, Medical University,

Gdansk, Poland 